\title{
To switch or not to switch: results of a nationwide guideline of mandatory switching from originator to biosimilar etanercept. One-year treatment outcomes in 2061 patients with inflammatory arthritis from the DANBIO registry
}

Bente Glintborg, ${ }^{1,2}$ Anne Gitte Loft, ${ }^{3,4}$ Emina Omerovic, ${ }^{5}$ Oliver Hendricks, ${ }^{6}$ Asta Linauskas, ${ }^{7}$ Jakob Espesen, ${ }^{8}$ Kamilla Danebod, ${ }^{2}$ Dorte Vendelbo Jensen, ${ }^{2}$ Henrik Nordin, ${ }^{9}$ Emil Barner Dalgaard, ${ }^{10}$ Stavros Chrysidis, ${ }^{11}$ Salome Kristensen, ${ }^{12}$ Johnny Lillelund Raun, ${ }^{13}$ Hanne Lindegaard, ${ }^{14}$ Natalia Manilo, ${ }^{15}$ Susanne Højmark Jakobsen, ${ }^{16}$ Inger Marie Jensen Hansen, ${ }^{16}$ Dorte Dalsgaard Pedersen, ${ }^{17}$ Inge Juul Sørensen, ${ }^{18,19}$ Lis Smedegaard Andersen, ${ }^{20}$ Jolanta Grydehøj, ${ }^{21}$ Frank Mehnert, ${ }^{22}$ Niels Steen Krogh, $^{23}$ Merete Lund Hetland ${ }^{18,19}$

\begin{abstract}
Handling editor Josef $S$
Smolen

- Additional material is published online only. To view please visit the journal online (http://dx.doi.org/10.1136/ annrheumdis-2018-213474).

For numbered affiliations see end of article.
\end{abstract}

\section{Correspondence to}

Dr Bente Glintborg, The DANBIO registry, Rigshospitalet, and Department of Rheumatology, Gentofte and Herlev University Hospital, Hellerup 2730 Denmark; glintborg@dadlnet.dk

Results have previously been presented as abstracts at the EULAR European Congress of Rheumatology 2017 (ARD, Vol 76. Suppl 2, p 553) and 2018 (ARD, Vol 77, Suppl, p A595) and the Scandinavian Congress of Rheumatology 2018 (PP66, PP67).

Received 26 March 2018 Revised 10 October 2018 Accepted 16 October 2018 Published Online First

5 November 2018

Check for updates

(c) Author(s) (or their employer(s)) 2019. No commercial re-use. See rights and permissions. Published by BMJ.

To cite: Glintborg $B$ Loft AG, Omerovic $E$, et al. Ann Rheum Dis 2019:78:192-200.

\section{ABSTRACT}

Objectives Real-world evidence on effectiveness of switching to biosimila r etanercept is scarce. In Denmark, a nationwide guideline of mandatory switch from $50 \mathrm{mg}$ originator (ETA) to biosimilar (SB4) etanercept was issued for patients with rheumatoid arthritis (RA), psoriatic arthritis (PsA) and axial spondyloarthritis (AxSpA) in 2016. Clinical characteristics and treatment outcomes were studied in ETA-treated patients, who switched to SB4 (switchers) or maintained ETA (non-switchers). Retention rates were compared with that of a historic cohort of ETA-treated patients. Switchers who resumed ETA treatment (backswitchers) were characterised.

Methods Observational cohort study based on the DANBIO registry. Treatment retention was explored by Kaplan-Meier plots and Cox regression (crude, adjusted). Results 1621 (79\%) of 2061 ETA-treated patients switched to SB4. Disease activity was unchanged 3 months' preswitch/postswitch. Non-switchers often received $25 \mathrm{mg}$ ETA (ETA $25 \mathrm{mg}$ pens/syringes and powder solution were still available). One-year adjusted retention rates were: non-switchers: $77 \%$ (95\% Cl: $72 \%$ to $82 \%) /$ switchers: $83 \%$ (79\% to $87 \%)$ /historic cohort: $90 \%$ (88\% to $92 \%$ ). Patients not in remission had lower retention rates than patients in remission, both in switchers (crude HR 1.7 (1.3 to 2.2)) and non-switchers (2.4 (1.7 to 3.6)). During follow-up, 120 patients (7\% of switchers) back-switched to ETA. Back-switchers' clinical characteristics were similar to switchers, and reasons for SB4 withdrawal were mainly subjective.

Conclusion Seventy-nine per cent of patients switched from ETA to SB4. After 1 year, adjusted treatment retention rates were lower in switchers versus the historic ETA cohort, but higher than in non-switchers. Withdrawal was more common in patients not in remission. The results suggest that switch outcomes in routine care are affected by patient-related factors and non-specific drug effects.

\section{Key messages}

What is already known about this subject?

- Real-world evidence on effectiveness of switching from originator to biosimilar etanercept in inflammatory arthritis is scarce.

What does this study add?

- Despite national mandatory guidelines, $\approx 20 \%$ of Danish patients treated with originator etanercept did not switch to biosimilar SB4.

- Baseline characteristics differed among patients who switched (switchers) and patients who maintained treatment (non-switchers).

- Adjusted treatment retention rates were lower in switchers than in a historic cohort, but higher than in non-switchers.

- Withdrawal was more common in patients not in remission.

How might this impact on clinical practice?

- Switch outcomes in routine care seem affected by patient-related factors and non-specific drug effects.

With the marketing of the first biosimilar disease-modifying antirheumatic drugs (bDMARDs) a new era has started, in which effective treatment of inflammatory arthritis at lower costs can be expected. ${ }^{12}$ A biosimilar must have equivalent efficacy and comparable safety to its reference product, and an immunogenicity not greater than that of its reference product. ${ }^{3}$

In 2015, the first biosimilar etanercept (SB4), was approved in Europe. ${ }^{3-5}$ At the time of marketing, SB4 had only been tested in patients with rheumatoid arthritis (RA). ${ }^{6}$ However, SB4 is also prescribed in for example, psoriatic arthritis (PsA) and axial spondyloarthritis (AxSpA), corresponding to the 
approved indications of the originator drug. ${ }^{78}$ This is theoretically of importance since age, genetics, comedication with conventional synthetic DMARDs and drug dose differ across diseases and may affect immunogenicity, pharmacokinetics and dynamics. ${ }^{5-11}$ Furthermore, patients included in randomised controlled trials (RCTs) differ from patients treated in routine care who are often older, have more comorbidities or atypical disease presentation. ${ }^{12}$ Thus, real-world evidence through postmarketing monitoring of safety across indications and long-term effectiveness outcomes in nationwide registries with prospective follow-up in routine care is a valuable supplement to RCTs. ${ }^{13-15}$

A Danish national guideline issued in April 2016 stated that all patients with inflammatory arthritis treated with originator etanercept (ETA) (Enbrel) must switch to SB4 (Benepali, 50 mg subcutaneous) for economic reasons. ${ }^{16}$ On marketing in Denmark, 50 mg SB4 costed 49\% less than ETA. Based on data from the nationwide DANBIO registry, we have previously reported outcomes after a similar non-medical switch from originator to biosimilar infliximab (CT-P13) performed the previous year in 802 patients with arthritis. ${ }^{17}$ Switch outcomes for the two biosimilars might differ due to different active substances (monoclonal antibodies vs receptor fusion protein) and increasing experience with, and confidence in, the use of biosimilars in patients and community over time. Furthermore, different administration routes (intravenous vs subcutaneous) might affect pharmacokinetics and healthcare behaviour (treatment given in hospital vs at home, close vs scarce contact to healthcare personnel), and for a subcutaneously administered biosimilar, the injection device might differ from the reference product. Finally, at the time of marketing of the biosimilars in Denmark, originator ETA was still available (25 mg syringes/ pens, $50 \mathrm{mg}$ powder solution), whereas originator infliximab was unavailable. Knowledge on real-world switching from ETA to SB4 is scarce. ${ }^{18-20}$

The aims of this nationwide, observational study were to investigate in ETA-treated patients (1) the proportions of patients who switched to SB4 (switchers) or maintained ETA treatment (non-switchers). Furthermore to investigate in switchers: (2) 3 months' disease activity before/after switching, (3) reasons for withdrawal, safety events and patient characteristics associated with withdrawal, (4) frequency, characteristics and outcomes of switch patients who resumed ETA (back-switchers) and to compare in switchers and non-switchers: (5) the 1-year retention rates with that of a historic cohort of ETA-treated patients. Finally, we aimed to characterise non-switchers including reasons for withdrawal.

\section{METHODS}

DANBIO covers $>95 \%$ of adults with rheumatic diseases treated in routine care with bDMARDs. ${ }^{2122}$ According to national treatment guidelines, disease activity and outcomes are monitored 1-2 times annually, and when medication is changed. ${ }^{21}$ The current study was approved by the Data Protection Agency (RH-2015-209, I-Suite 04145). In Denmark, registry research neither requires patient consent nor ethical approval.

Patients with RA, PsA and AxSpA treated with ETA by 1 April 2016 were identified in DANBIO. The following cohorts were defined: switchers: patients who switched from ETA to SB4 between 1 April 2016 and 1 January 2017. A time gap of 0-90 days between stop of ETA and start of SB4 was allowed to comply with differences in registration practice. Non-switchers: the group of ETA-treated patients who did not switch to SB4 during follow-up. Back-switchers: switchers, who stopped SB4 and resumed treatment with ETA during follow-up. Furthermore, a historic comparison cohort of ETA-treated patients by 1 January 2015 was identified in DANBIO.

Eighteen of 23 departments of rheumatology in Denmark accepted to validate DANBIO data regarding switch date, disease activity and reasons for SB4 withdrawal. Thus, $84 \%$ of included treatment series were validated. Data were censored by 28 August 2017. The data collection in DANBIO has been described previously. ${ }^{21}$ For switchers, the index date (baseline) was the date of switch to SB4 from ETA. For non-switchers, the index date was 1 April 2016 and for the historic cohort 1 January first 2015.

Through linkage by social security numbers, comorbidities (Charlson Comorbidity Index, excluding musculoskeletal comorbidity) ${ }^{23}$ from index date and 10 years back were identified in the Danish National Patient Registry, which has complete data regarding hospitalisations and outpatient care. ${ }^{24}$ Vital status was obtained from the Danish Civil Registry.

\section{Statistics}

Descriptive data are presented by medians (IQR) or as numbers (percentages) for discrete data. Non-parametric statistics were used for comparisons of patient characteristics $\left(\mathrm{X}^{2}\right.$ or MannWhitney tests as appropriate). Unless otherwise stated, analyses were based on available data with no imputation of missing data.

In switchers, disease activity 3 months before switch (preswitch), at the time of switch, after 3 months (postswitch) and changes over time ( $\Delta$ preswitch and $\Delta$ postswitch) were calculated in each patient. Predefined time windows were applied for measures of disease activity. Missing data at the 3 months' visit was imputed with the 6 months' visit. For patients who withdrew $\leq 3$ months postswitch $(\mathrm{n}=105)$, data from the latest registered visit after baseline were carried forward. Disease flare in patients with RA and PsA was defined as (1) changes in 28-joint Disease Activity Score (DAS28) $\geq 0.6$ and (2) $\triangle \mathrm{DAS} 28 \geq 1.2$. In AxSpA, $\Delta$ (Ankylosing Spondylitis)ASAS Disease Activity Score (ASDAS) $\geq 1.1$ was considered a flare. Remission was defined as DAS28 $<2.6$ and ASDAS $<1.3$, respectively.

Retention rate was the proportion of patients who maintained the same drug in a given time period. Retention rates (=drug survival) in switchers, non-switchers, and the historic cohort was explored with Kaplan-Meier plots and log rank tests. Multiple Cox proportional hazards regression analyses and HRs stratified by indication (RA/PsA/AxSpA) were conducted to estimate withdrawal rates adjusted for clinically relevant baseline variables. Comparisons were performed as two sets of analyses: switchers versus the historic cohort and switchers versus non-switchers. The following baseline variables were included: age, gender, methotrexate (MTX) (yes/no), comorbidities $(0 / \geq 1)$, remission (yes/no) and ETA start year (1998-2010/2011-2016). Similarly, adjusted 1-year retention rates with 95\% CI were calculated. In the comparison of switchers versus the historic cohort, robust variance calculation was applied to account for repeated subjects with left truncation of events (1 January 2015), and all observations were censored after 1 year. Baseline data were complete for all covariates except remission status, which was available in $79 \%$ of switchers, $92 \%$ of non-switchers and $91 \%$ of patients in the historic cohort.

Since remission status was closely associated with patient's global score (PGS), additional multiple Cox regression analyses were performed for sensitivity, in which remission status (yes/no) was replaced by PGS (categorical: $\leq 30 \mathrm{~mm} />30 \mathrm{~mm}$ ). 
Table 1 Baseline demographics in patients who switched from originator etanercept (ETA) to biosimilar etanercept (SB4) and in patients who maintained ETA treatment (non-switchers) stratified by indication. One-year treatment retention and reasons for withdrawal are also shown

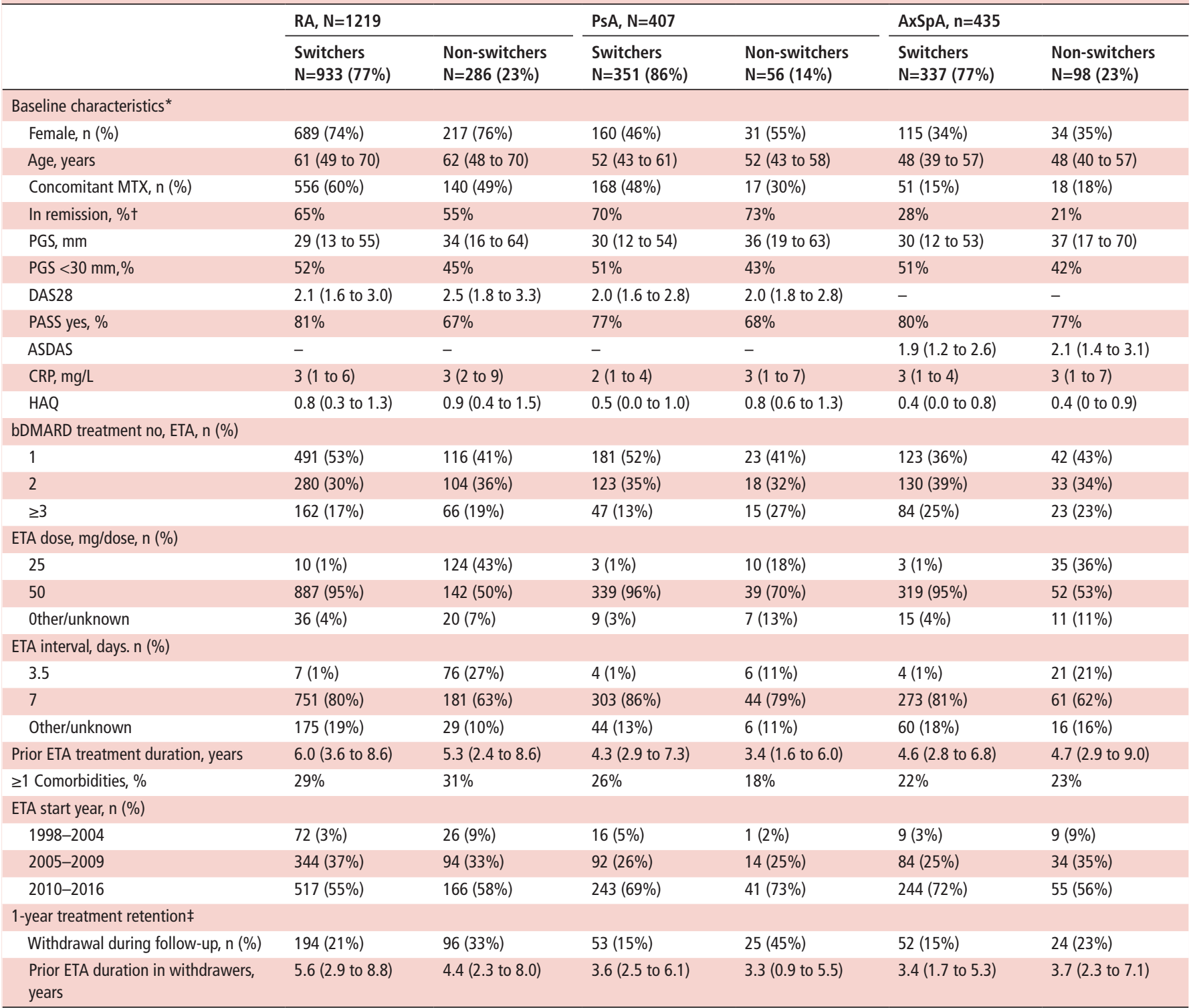

Numbers are medians (interquartile ranges) unless otherwise stated.

*Baseline is according to first SB4 dose ( -90 to +6 days) for switchers and according to 1 April 2016 ( \pm 180 days) for non-switchers. tDAS28 <2.6 (RA, PsA), ASDAS <1.3 (AxSpA).

¥Median follow-up switchers: 383 (314-414) days, non-switchers: 483 (222-483) days.

ASDAS, the Ankylosing Spondylitis Disease Activity Score; AxSpA, axial spondyloarthritis; CRP, C reactive protein; DAS, Disease Activity Score; HAQ, Health Assessment Questionnaire; MTX, methotrexate; PASS, patient acceptable symptom state; PGS, patient's global score; PsA, psoriatic arthritis; RA, rheumatoid arthritis; bDMARDs, biosimilar disease-modifying antirheumatic drugs.

For back-switchers, disease activity at the SB4 index date and at the time of back-switching to ETA were compared, and changes (=delta values) were calculated in each patient. Delta values were reported as medians (IQR) stratified by indication (RA/PsA/AxSpA). Baseline characteristics of back-switchers (gender, age, PGS, swollen joint count (RA, PsA), C reactive protein) were compared with the rest of the switch population.

Statistical analyses were performed by SPSS (V.22) and SAS (V.9.4). P values $<0.05$ were considered statistically significant.

\section{RESULTS}

Among 2183 ETA-treated patients identified in DANBIO, 2061 patients were included of which 1621 (79\%) switched to SB4 (see online supplementary figure 1, table 1). In $49 \%$ of switchers, ETA was the first bDMARD, and prior to switching 99\% received $50 \mathrm{mg}$ and 1\% $25 \mathrm{mg}$ ETA doses. In non-switchers, ETA was the first bDMARD in 41\%, and prior to the index date $34 \%$ received $25 \mathrm{mg}$ ETA doses (55\% twice weekly, 31\% once weekly, $14 \%$ unknown or other intervals).

\section{Baseline characteristics of switchers and non-switchers}

Among patients with RA, AxSpA and PsA, 77\%, 77\% and 86\%, respectively switched to SB4 (table 1). Switchers more frequently received concomitant MTX than non-switchers (in RA and PsA), whereas gender and age distributions stratified by indication were similar (table 1). Switchers had longer previous ETA treatment duration and fewer previous bDMARDs compared with non-switchers. At baseline, switchers with RA had lower disease 
Table 2 Disease activity 3 months prior to vs 3 months after the switch from ETA to SB4 stratified by indication

\begin{tabular}{|c|c|c|c|c|c|}
\hline & \multicolumn{3}{|l|}{ Disease activity } & \multicolumn{2}{|l|}{ Changes over time } \\
\hline & 3 months preswitch & Switch & 3 months postswitch & $\Delta$ Preswitch & $\Delta$ Postswitch \\
\hline \multicolumn{6}{|l|}{$R A, n=933$} \\
\hline Patients with available data, $\mathrm{n}(\%)^{*}$ & $639(68)$ & $745(80)$ & $568(61)$ & $485(52)$ & $436(47)$ \\
\hline DAS28 & 1.9 (1.3 to 2.8$)$ & $2.1(1.6$ to 3.0$)$ & 2.1 (1.7 to 3.1$)$ & $0.0(0.0$ to 0.0$)$ & $0.0(-0.4$ to 0.5$)$ \\
\hline $\mathrm{HAQ}(0-3)$ & $0.8(0.3$ to 1.3$)$ & $0.8(0.3$ to 1.3$)$ & $0.8(0.3$ to 1.3$)$ & $0(-1$ to 1$)$ & $0(-1$ to 1$)$ \\
\hline CRP, mg/L & $3(1$ to 7$)$ & $3(1$ to 6$)$ & $3(1$ to 6$)$ & $0(-2$ to 1$)$ & $0(-1$ to 1$)$ \\
\hline PGS, mm & $30(14$ to 57$)$ & 29 (13 to 55$)$ & 32 (12 to 62$)$ & 0 (-11 to 8$)$ & $1(-8$ to 11$)$ \\
\hline \multicolumn{6}{|l|}{ PsA, $n=351$} \\
\hline Patients with available data, $\mathrm{n}(\%)^{*}$ & $223(64)$ & $253(72)$ & $197(56)$ & $158(45)$ & $152(43)$ \\
\hline DAS28 & 1.8 (1.1 to 2.4$)$ & $2.0(1.6$ to 2.8$)$ & 2.1 (1.5 to 2.8$)$ & $0.0(0.0$ to 0.0$)$ & $0.1(-0.4$ to 0.5$)$ \\
\hline HAQ (0-3) & $0.5(0.1$ to 1.0$)$ & $0.5(0.0$ to 1.0$)$ & $0.5(0.1$ to 1.0$)$ & $0.0(-0.1$ to 0.1$)$ & $0.0(-0.1$ to 0.1$)$ \\
\hline CRP, mg/L & $2(1$ to 4$)$ & 2 (1 to 4) & $2(1$ to 4$)$ & $0(-2$ to 1$)$ & $0(-1$ to 1$)$ \\
\hline PGS, mm & 33 (13 to 58$)$ & $30(12$ to 54$)$ & 31 (12 to 58$)$ & $0(-9$ to 6$)$ & $0(-7$ to 10$)$ \\
\hline \multicolumn{6}{|l|}{ AxSpA, $n=337$} \\
\hline Patients with available data, $\mathrm{n}(\%)^{*}$ & $187(55)$ & $217(64)$ & $243(72)$ & $117(35)$ & $168(50)$ \\
\hline BASDAI, mm & 33 (15 to 52$)$ & 27 (12 to 47$)$ & 31 (18 to 52$)$ & $0(-8$ to 6$)$ & $1(-3$ to 10$)$ \\
\hline CRP, mg/L & $3(1$ to 6$)$ & $3(1$ to 5$)$ & $3(1$ to 5$)$ & $0(-2$ to 1$)$ & $0(-1$ to 1$)$ \\
\hline PGS, mm & $32(15$ to 59$)$ & 30 (12 to 53$)$ & $34(17$ to 60$)$ & $-1(-13$ to 6$)$ & $3(-5$ to 14$)$ \\
\hline ASDAS & $1.9(1.3$ to 2.8$)$ & $1.9(1.2$ to 2.6$)$ & $1.9(1.3$ to 2.7$)$ & $-0.1(-0.4$ to 0.3$)$ & $0.1(-0.2$ to 0.6$)$ \\
\hline \multicolumn{6}{|c|}{3 months' flare rates preswitch vs postswitch $†$} \\
\hline $\mathrm{RA}(\triangle \mathrm{DAS} 28 \geq 0.6), \%$ & & & & 22 & 24 \\
\hline $\operatorname{PsA}(\triangle D A S 28 \geq 0.6), \%$ & & & & 21 & 23 \\
\hline $\mathrm{RA}(\triangle \mathrm{DAS} 28 \geq 1.2), \%$ & & & & 8 & 13 \\
\hline $\operatorname{PsA}(\triangle \mathrm{DAS} 28 \geq 1.2), \%$ & & & & 8 & 11 \\
\hline AxSpA $(\triangle \mathrm{ASDAS}>1.1), \%$ & & & & 4 & 5 \\
\hline
\end{tabular}

Numbers are medians (interquartile ranges) unless otherwise stated (\%).

Missing data at the 3 months' visit were imputed with the 6 months' visit according to the following time windows:

Time windows preswitch: 3 months' window: 0 to 25 weeks, 6 months' window: 25 to 32 weeks before start of SB4.

Time window switch: 12 weeks before until 1 week after start of SB4.

Time window postswitch: 3 months' window: 9 to 17 weeks, 6 months' window: 17 to 32 weeks after start of SB4. Overlapping time windows at baseline were allowed to reduce missing data. Any visit was only used once, and the registration closest to the given time point was selected. If a patient had no registrations, data were registered as missing for that visit.

* Number of patients with available data varied slightly across measures of disease activity. Exact numbers are shown for DAS28 and ASDAS. Individual patients might not have complete data for all variables at a certain time point. Comparisons of before vs after the switch were done in the patients who had complete data for that variable.

tThere was no overlap between the patients who had a flare preswitch vs postswitch.

$\ddagger$ Comparison of $\triangle$ preswitch vs $\triangle$ postswitch byWilcoxon matched-pair signed rank test.

ASDAS, the Ankylosing Spondylitis Disease Activity Score; AxSpA, axial spondyloarthritis; BASDAl, Bath Ankylosing Spondylitis Disease Activity Index; CRP, C reactive protein; DAS28, 28-joint Disease Activity Score (four variables, CRP-based); ETA, originator etanercept; HAQ, Health Assessment Questionnaire; PGS, patient's global score; PsA, psoriatic arthritis; RA, rheumatoid arthritis; SB4, biosimilar etanercept.

activity than non-switchers. A similar pattern was observed for PsA (mainly for the subjective measures PGS, PASS) and AxSpA (table 1). Available data are shown in online supplementary table S1. The percentage of patients with available data regarding baseline remission status was $71 \%$ for switchers and $90 \%$ for non-switchers.

\section{Outcomes in switchers and non-switchers}

In switchers, disease activity and flare rates 3 months preswitch versus postswitch were similar with no clinically relevant differences (table 2). For RA and PsA, two different definitions of disease flare were applied (table 2).

During follow-up (median 401 days (IQR: 336 to 443 days), 299 switchers (18\%) and 145 non-switchers (33\%) withdrew from treatment with SB4 and ETA, respectively. In both patient groups, lack of effect was the most common reason for withdrawal (table 3). In switchers, adverse events were mainly unspecific, and no major safety signals were observed (table 3).

Among switchers, the SB4 retention rate was lower in patients with RA (figure 1A), in patients who had started ETA treatment during the later years (overall, figure $1 \mathrm{~B}$, and stratified by indication, not shown) and in patients not in remission at the time of switching (overall, figure 1C, HR 1.7 (95\% CI 1.3 to 2.2) and stratified by indication, not shown). Similarly, in the cohort of non-switchers, retention rate was lower in patients not in remission (HR 2.4 (1.7 to 3.6)) and in patients who started treatment during the later years, and withdrawal was more frequent in PsA (all $\mathrm{p}<0.01$, not shown).

When comparing retention rates in switchers with non-switchers stratified by indication, switchers were less likely to withdraw from treatment than non-switchers (crude HR for withdrawal ranging from 0.42 to 0.89 , most pronounced in RA and PsA) (table 4). In adjusted analyses, switch status was no longer statistically significant (table 4). Similar results were found in sensitivity analyses replacing remission status with PGS ( $\leq 30 \mathrm{~mm} />30 \mathrm{~mm}$ ) as baseline covariate (not shown).

\section{Switchers versus historic cohort, one-year retention rates}

A historic cohort of patients treated with ETA by 1 January 2015 was identified in DANBIO $(n=2363)$. The percentage of 


\begin{tabular}{|c|c|c|}
\hline & $\begin{array}{l}\text { Switchers } \\
N=1621\end{array}$ & $\begin{array}{l}\text { Non-switchers } \\
\mathrm{N}=440\end{array}$ \\
\hline \multicolumn{3}{|c|}{ Reason, $n$ (\% of withdrawals) } \\
\hline Lack of effect & $137(46)$ & $48(34)$ \\
\hline Adverse events & $77(26)^{*}$ & $14(10)$ \\
\hline Several reasons & 9 (3) & $1(1)$ \\
\hline Cancer & $6(2)$ & $11(8)$ \\
\hline Remission & $8(3)$ & $10(7)$ \\
\hline Pregnancy & $4(1)$ & $3(2)$ \\
\hline Death & $9(3)$ & $15(10)$ \\
\hline Infection & $3(1)$ & $8(6)$ \\
\hline Loss to follow-up & $1(2)$ & $9(6)$ \\
\hline Surgery & $2(1)$ & $1(1)$ \\
\hline Other & $14(5)$ & $18(13)$ \\
\hline Not stated & $29(10)$ & 7 (5) \\
\hline Withdrawals, total, n (\%) & $299(100)$ & $145(100)$ \\
\hline
\end{tabular}

${ }^{*}$ Adverse events during biosimilar etanercept (SB4) treatment in switchers (77 patients): anxiety 1 patient, arthralgia 1, bladder dysfunction 1, blurred vision 1 , chest pain 2 , diarrhoea 4 , dizziness 2 , dyspnoea 2 , erectile dysfunction 1 , fatigue 1 , fever 2, hair loss 1 , headache/migraine 9, hyperhidrosis 2, hypertension 1 , hypotension 1, infections 2, leg cramps 2, leucopenia 3, local injection problems 3 , myalgia 2, nausea 4, neuropathies 1 , psoriasis worsening or pustulosis 2 , rash/ itching 11, not stated 39 (total=101 events).

patients from the cohorts of switchers, non-switchers and backswitchers that were also included in the historic cohort were $94 \%, 86 \%$ and $100 \%$, respectively. Furthermore, 376 patients were only in the historic cohort and were not included in the switch/non-switch cohorts. The baseline demographics of the historic and the switch cohort were similar (see online supplementary table S2). The 1-year crude retention rate was lower in switchers (82\% (95\%CI: $79 \%$ to $83 \%)$ ) than in the historic cohort $(88 \%(87 \%$ to $90 \%))$ but better than in non-switchers $(70 \%(66 \%$ to $74 \%))$ (figure 1D). The corresponding 1-year adjusted retention rates were $83 \%(79 \%$ to $87 \%))$ in switchers, $90 \%(88 \%$ to $92 \%))$ in the historic cohort and $77 \%(72 \%$ to $82 \%)$ ) in non-switchers. In adjusted analysis of treatment withdrawal in switchers compared with the historic cohort, switch status remained significant (table 4). Similar results were found in sensitivity analyses replacing PGS with remission status as baseline covariate (not shown).

\section{Frequency and outcomes of back-switching}

During follow-up, the 299 switchers, who had withdrawn SB4 therapy, either commenced treatment with another bDMARD $(n=104)$, switched back to ETA $(n=120)$, died $(n=9)$, were lost to follow-up $(n=1)$ or did not restart bDMARDs $(n=65)$ (see online supplementary table S2).

Among the 120/1641 switchers (7\%) who withdrew from treatment with SB4 and switched back to ETA, the main reason for SB4 withdrawal was lack of effect (table 5). Baseline characteristics were similar in back-switchers and the rest of the switch population (all $\mathrm{p}>0.05$ ). Changes in disease activity at the time of ETA restart compared with SB4 index date were mainly observed for PGS whereas changes in CRP and swollen joint counts were close to zero (table 5). The SB4 treatment duration before back-switching to ETA was median 120 (IQR 73 to 193) days, and the time interval between stop of SB4 and restart of ETA was 1 (1-1) days. At the time of censoring, 104 of 120 back-switchers (87\%) were still treated with ETA with median treatment duration of 236 (155 to 302) days.

\section{DISCUSSION}

In the current study, treatment outcomes of a nationwide guideline with mandatory switching from ETA to SB4 were investigated in 2061 patients of whom 79\% switched to biosimilar SB4. The 21\% non-switchers less frequently had PsA and tended to have higher disease activity than the switchers and received concomitant MTX less frequently (in patients with PsA and RA). Some non-switchers received the $25 \mathrm{mg}$ ETA dose, which was still available. Regarding treatment outcomes, this study showed mixed results. On one hand, the disease activity among switchers was stable 3 months before and after the switch. On the other hand, the 1-year SB4 retention rate was lower than that of a historic ETA cohort. However, the non-switch cohort had even higher withdrawal rate. Our study indicates that patient-related factors, for example, being in remission or not, rather than drug (originator or biosimilar) were important for the decision to withdraw treatment. A subgroup of SB4-treated patients switched back to ETA. They had no distinct clinical or disease characteristics at the start of SB4, and reasons for back-switching appeared to be of a more subjective rather than objective nature.

According to recent European League Against Rheumatism (EULAR) recommendations, biosimilars should be included in the treatment algorithm on equal terms as the originator drugs. ${ }^{25}$ However, regarding non-medical switching (ie, switching for economic reasons in patients who are receiving treatment with the originator drug), recommendations are less clear. ${ }^{1}$ A recent task force concluded that a single switch from a bio-originator to one of its biosimilars is safe and effective ${ }^{8}-\mathrm{a}$ recommendation that has been debated by others. ${ }^{15}$ Currently, the use of biosimilars and switch procedures in routine care vary substantially across countries. ${ }^{26-28}$

Experience regarding real-world use of biosimilar drugs is needed as a supplement to RCTs. ${ }^{8} 152829$ Thus, RCTs mainly report outcomes in highly selected and often bDMARD naïve patients with short follow-up, ${ }^{6}$ whereas observational studies provide data in large unselected patient -groups that may be switchers from other bDMARDs and with the opportunity of long follow-up. To our knowledge, this study is the largest to explore outcomes of a non-medical switch from originator ETA to SB4 in routine care. ${ }^{18-2030}$ We observed no new major safety events for SB4. The efficacy and safety profile of switching from ETA to SB4 has been demonstrated in one RCT of patients with moderate-severe RA despite previous MTX treatment ${ }^{6}{ }^{31}$ where a subgroup of patients initially randomised to ETA treatment $(n=119)$ after 1 year switched to SB4 in an open label design. ${ }^{4}$ The authors reported no excess risk and comparable efficacy, safety and immunogenicity in the switch group compared with patients who continued treatment with SB4. ${ }^{4}$ Previous observational studies (abstracts only) have, similar to our findings, reported stable disease activity 6 months after switching ${ }^{19}$ (147 patients) and a 6 months' SB4 withdrawal rate of 9\%-10\% (in two cohorts of 92 and 642 patients, respectively). ${ }^{182}$

Although the Danish guideline that preceded the current study stated that the switch was mandatory, $21 \%$ remained on ETA treatment in contrast to a previous mandatory switch to biosimilar infliximab. ${ }^{17}$ The originator drug was still available (as $25 \mathrm{mg}$ syringe/pen or as $50 \mathrm{mg}$ powder solution) which may partly explain why one in five patients did not switch. Most non-switchers received $50 \mathrm{mg}$ ETA. Patient-related factors, for example, more comorbidities (indicated by more deaths, infections and cancers during follow-up), and 

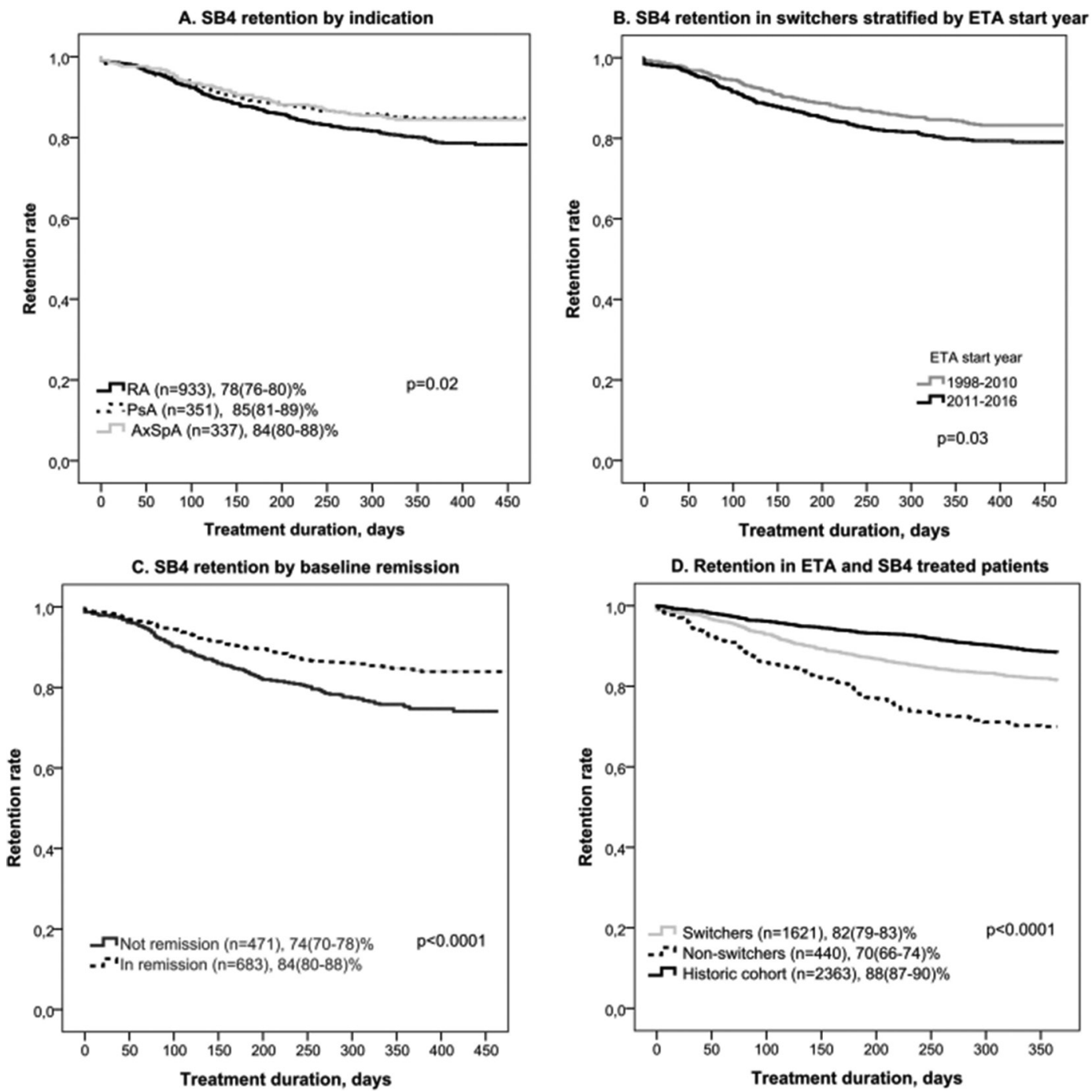

Figure 1 Kaplan-Meier plots of crude treatment retention rates among SB4 switch patients. (A) Stratified by indication. (B) Stratified by start year of ETA treatment (all indications) (. (C) Stratified by baseline remission (all indications). (D) Compared with non-switchers and a historic ETA cohort (all indications). Percentages are 1-year treatment retention (95\% CI). AxSpA, axial spondyloarthritis; ETA, originator etanercept; PsA, psoriatic arthritis; RA, rheumatoid arthritis; SB4, biosimilar etanercept.

higher disease activity in non-switchers might have contributed to non-switch. Thus, the study results are likely biassed by the fact that the final outcomes (drug retention, remission status, etc) were influenced by the patient's and physician's choice to comply with the guideline (and agreed in switching) or refused to do so (and did not switch). An indication for the presence of such bias can be found in the baseline differences between switchers and non-switchers. In that regard, the

Table 4 Treatment retention in (A) switchers vs non-switchers and (B) switchers vs historic cohort. Results from univariable and multivariable Cox regression analysis ( $\mathrm{HR}$, with $95 \% \mathrm{Cl})$ stratified by indication

\begin{tabular}{|c|c|c|c|c|c|c|}
\hline & \multicolumn{2}{|l|}{ RA } & \multicolumn{2}{|l|}{ PsA } & \multicolumn{2}{|l|}{ AxSpA } \\
\hline & HR & $P$ values & HR & $P$ values & HR & $P$ values \\
\hline \multicolumn{7}{|c|}{ A. Switchers vs non-switchers* } \\
\hline Crude & $0.68(0.51$ to 0.91$)$ & 0.0005 & 0.42 (0.24 to 0.73 ) & 0.0019 & $0.89(0.49$ to 1.60$)$ & 0.70 \\
\hline Adjusted $\dagger$ & 0.81 (0.59 to 1.11$)$ & 0.18 & 0.55 (0.28 to 1.07$)$ & 0.079 & 0.92 (0.50 to 1.73$)$ & 0.82 \\
\hline \multicolumn{7}{|c|}{ B. Switchers vs historic comparison cohort* } \\
\hline Crude & 1.73 (1.36 to 2.19$)$ & $<0.0001$ & 1.93 (1.26 to 2.96$)$ & 0.0024 & 2.29 (1.45 to 3.61$)$ & 0.0003 \\
\hline Adjusted $t$ & 1.76 (1.39 to 2.23$)$ & $<0.0001$ & 2.15 (1.42 to 3.25$)$ & 0.0003 & 2.37 (1.51 to 3.73$)$ & 0.0002 \\
\hline
\end{tabular}

${ }^{*}$ Number of patients included in cohorts: RA (switchers 684 patients/non-switchers 264/historic cohort 1239), PsA (253/49/364), AxSpA (217/81/412), patients with missing data regarding remission status excluded.

tAdjusted for gender, age, methotrexate use (yes/no), remission (yes/no), comorbidities ( $\geq 1 / 0)$, ETA start year (1998-2010/2011-2016). Remission defined as DAS28 <2.6 (RA, PsA), ASDAS <1.3 (AxSpA).

ASDAS, the Ankylosing Spondylitis Disease Activity Score; AxSpA, axial spondyloarthritis; CRP, C reactive protein; DAS28, 28-joint Disease Activity Score (four variables, CRPbased); ETA, originator etanercept; PGS, Patient's globalscore; PsA, psoriatic arthritis; RA, rheumatoid arthritis. 
Table 5 ETA-SB4-ETA back-switchers $(n=120)$. Characteristics at the start of SB4, reasons for SB4 withdrawal and changes in disease activity among withdrawals due to LOE

\begin{tabular}{|c|c|c|c|}
\hline & RA & PsA & AxSpA \\
\hline Patient number, $\mathrm{n}$ & 80 & 20 & 20 \\
\hline \multicolumn{4}{|l|}{ Characteristics at the start of SB4 } \\
\hline Female, $n(\%)$ & $58(73)$ & $11(55)$ & $7(35)$ \\
\hline Age, years & 59 (52 to 70$)$ & 45 (36 to 56 ) & 43 (38 to 56$)$ \\
\hline Concomitant MTX, n (\%) & $39(49)$ & $7(35)$ & $1(5)$ \\
\hline Patients with available data, $\mathrm{n}^{*}$ & 64 & 17 & 18 \\
\hline In remission, \% & 61 & 82 & 19 \\
\hline PGS, mm* & 27 (12 to 54$)$ & 25 (13 to 63$)$ & 23 (13 to 44$)$ \\
\hline DAS28 & $2.2(1.6$ to 3.2$)$ & $1.8(1.4$ to 2.2$)$ & - \\
\hline $\mathrm{CRP}, \mathrm{mg} / \mathrm{L}$ & $3(1$ to 8$)$ & 1 (1 to 5$)$ & $3(1$ to 6$)$ \\
\hline Swollen joint count & 0 (0 to 1$)$ & $0(0$ to 0$)$ & - \\
\hline ASDAS & - & - & 1.7 (1.4 to 2.4$)$ \\
\hline PASS yes, $\%$ & 81 & 82 & 88 \\
\hline \multicolumn{4}{|l|}{ Reason for SB4 withdrawal, n (\%) } \\
\hline $\mathrm{AE}$ & $34(42)$ & $7(35)$ & $6(30)$ \\
\hline LOE & $38(48)$ & $11(55)$ & $13(65)$ \\
\hline Other/several/not stated & $8(10)$ & $2(10)$ & $1(5)$ \\
\hline \multicolumn{4}{|c|}{ Characteristics at the restart of ETA in patients who stopped due to LOE and back-switched, $n=62$} \\
\hline Patient number, $\mathrm{n}$ & 38 & 11 & 13 \\
\hline Swollen joint count & $2(0$ to 5$)$ & 0 (0 to 2$)$ & - \\
\hline $\mathrm{CRP}, \mathrm{mg} / \mathrm{L}$ & $3(2$ to 11$)$ & $3(2$ to 7$)$ & $4(1$ to 6$)$ \\
\hline PGS, mm & 64 (50 to 76$)$ & $78(18$ to 90$)$ & $42(35$ to 63$)$ \\
\hline \multicolumn{4}{|c|}{ Delta valuest in patients who stopped due to LOE and back-switched } \\
\hline Patients with available data, n† & 31 & 8 & 11 \\
\hline Delta-swollen joint count & $1(0$ to 4$)$ & $0(0$ to 0$)$ & - \\
\hline Delta-CRP, mg/L & $0(-1$ to 5$)$ & 1 (0 to 2$)$ & 0 (0 to 4$)$ \\
\hline Delta-PGS, mm & 30 (12 to 52$)$ & 15 (7 to 77 ) & 25 (19 to 35$)$ \\
\hline
\end{tabular}

Numbers are medians (interquartile ranges) unless otherwise stated.

Patients stopped due to adverse events, $\mathrm{n}=47$ : arthralgia 1 patient, bladder dysfunction 1, blurred vision 1, diarrhoea 4, dizziness 2, dyspnoea 2, erectile dysfunction 1 , hair loss 1 , headache/migraine 4, hyperhidrosis 2 , hypertension 1 , hypotension 1 , infections 2 , leg cramps 1 , local injection problems 3 , myalgia 1 , nausea 2, neuropathies 1 , psoriasis worsening or pustulosis 1 , rash/itching 9 , not stated 21 (total=62 events, this is a subgroup of the eventsshown in table 3 ).

*Available data varied according to variable, numbers are shown for PGS.

tCalculated as disease activity at time of restart ETA minus at the time of SB4 start for each patient.

AE, adverse event; ASDAS, the Ankylosing Spondylitis Disease Activity Score; AxSpA, axial spondyloarthritis; CRP, C reactive protein; DAS28, 28-joint Disease Activity Score (four variables, CRP-based); LOE, lack of effect; MTX, methotrexate; PASS, patient acceptable symptom state; PGS, patient's global score; PsA, psoriatic arthritis; RA, rheumatoid arthritis; SB4, biosimilar etanercept.

study results do not represent an unbiased comparison of the effects of switching versus non-switching, and other (patient related) factors than the switching alone may have influenced the outcomes.

Many ETA-treated patients were not in disease remission when they were switched to SB4 and they withdrew more often than patients who were in remission. We have previously reported similar results in patients who switched from originator to biosimilar infliximab. ${ }^{17}$ Interestingly, the same pattern was observed in patients who maintained ETA treatment (non-switchers). This suggests that a switching-to-biosimilar guideline facilitated clinical decision making and withdrawal of ineffective therapy independent of switch status.

The knowledge regarding biosimilar drugs in the general population and patients with chronic diseases is still low. ${ }^{32}$ Both physicians and patients may be reluctant to use biosimilars. ${ }^{233}$ The nocebo effect (ie, negative expectations towards a given treatment), patient-related factors and subjective health experiences may have influenced the perception of treatment outcomes and adverse events. ${ }^{34-39}$ The majority of the 120 back-switchers were still treated with ETA on data censoring. However, changes in disease activity and the reported AEs tended to be subjective rather than objective.

The study has strengths and weaknesses. We report nationwide, prospectively collected data in a large cohort of ETA-treated patients treated in routine care which strengthens external validity. Patients acted as their own controls in the evaluation of disease activity before/after switch, and outcomes could be compared with those of both a historic cohort and of a non-switch cohort. However, due to the observational study design, we report associations, not definitive causal relationships. Furthermore, residual confounding may affect results. Data were collected as part of routine care and missing data might bias results. Approximately half of patients contributed consecutive data on changes in disease activity 3 months prior to versus after the switch. Patients in remission are potentially monitored less frequently and the same might apply to frail patients with comorbidities. Data completeness was lower than in a previous publication from DANBIO describing switch from originator to biosimilar infliximab ${ }^{17}$ and may reflect less frequent monitoring of patients treated with subcutaneous (ie, self-administered) bDMARDs. 
In conclusion, we found that a nationwide switch from originator to biosimilar ETA in 1621 patients with inflammatory arthritis had no negative impact on 3 months' disease activities, and no major safety events were observed. Despite mandatory switch recommendations, one in five ETA-treated patients did not switch. In both patient groups, withdrawal was most common in patients not in remission. These real-world data indicate that switch outcomes in routine care are affected by non-specific drug effects and patient-related factors.

\section{Author affiliations}

The DANBIO registry and Copenhagen Center for Arthritis Research (COPECARE), Center for Rheumatology and Spine Diseases, Centre of Head and Orthopaedics, Rigshospitalet, Glostrup, Denmark

${ }^{2}$ Department of Rheumatology, Gentofte and Herlev Hospital, Copenhagen University Hospital, Gentofte, Denmark

${ }^{3}$ Department of Rheumatology, Aarhus University Hospital, Aarhus, Denmark

${ }^{4}$ Department of Clinical Medicine, Aarhus University, Aarhus, Denmark

${ }^{5}$ Department of Rheumatology, Center for Rheumatology and Spine Diseases, Centre of Head and Orthopaedics, Rigshospitalet, Copenhagen University Hospital, Glostrup, Denmark

${ }^{6}$ Kong Christian X's Gigthospital, Gråsten, Denmark

${ }^{7}$ Department of Rheumatology, North Denmark Regional Hospital, Hjørring, Denmark

${ }^{8}$ Department of Rheumatology, Vejle Hospital Lillebælt, Vejle, Denmark

${ }^{9}$ Department of Rheumatology, Zealand University Hospital, Køge, Denmark

${ }^{10}$ Department of Rheumatology, Silkeborg Hospital, Silkeborg, Denmark

${ }^{11}$ Department of Rheumatology, Esbjerg Hospital, Esbjerg, Denmark

${ }^{12}$ Department of Rheumatology, Aalborg University Hospital, Aalborg, Denmark

${ }^{13}$ Department of Rheumatology, Sygehus Lillebælt, Fredericia, Kolding, Denmark

${ }^{14}$ Department of Rheumatology, Odense University Hospital, Odense, Denmark

${ }^{15}$ Department of Rheumatology, Frederiksberg Hospital, Copenhagen, Denmark

${ }^{16}$ Department of Rheumatology, OUH, Svendborg Hospital, Svendborg, Denmark

${ }^{17}$ Department of Rheumatology, Viborg Hospital, Viborg, Denmark

${ }^{18}$ Department of Clinical Medicine, Faculty of Health and Medical Sciences, University of Copenhagen, Copenhagen, Denmark

${ }^{19}$ The DANBIO registry and COPECARE, Center for Rheumatology and Spine Diseases, Centre of Head and Orthopaedics, Rigshospitalet, Copenhagen University Hospital, Glostrup, Denmark

${ }^{20}$ Department of Internal Medicine, Rønne Hospital, Rønne, Denmark

${ }^{21}$ Department of Rheumatology, Holstebro hospital, Holstebro, Denmark

${ }^{22}$ Department of Clinical Epidemiology, Aarhus University Hospital, Aarhus, Denmark

${ }^{23}$ Zitelab Aps, Copenhagen, Denmark

Acknowledgements Thanks to all the Danish departments of rheumatology for reporting to the DANBIO registry.

Contributors BG, MLH: contributed to the study design. BG, MLH, NSK, FM: contributed to data analyses and interpretation. All authors contributed to data collection and contributed to and approved the final manuscript.

Funding The study was partly funded by a grant from Biogen, who had no influence on the study design, analyses, interpretation or the decision to publish the results.

Competing interests BG: AbbVie, Biogen, Pfizer, MSD. MLH: Orion, BMS, AbbVie, Biogen, Pfizer, MSD, Celltrion. IMJH: Roche. AGL: AbbVie, MSD, Novartis, Pfizer, Roche, UCB OH: AbbVie, Roche, Novartis. HN: AbbVie, Novartis, Medac. LSA: Pfizer. The remaining authors: none declared.

Patient consent Not required.

Ethics approval Observational registry.

Provenance and peer review Not commissioned; externally peer reviewed.

Data sharing statement No additional unpublished data are available.

\section{REFERENCES}

1 Schulze-Koops $\mathrm{H}$, Skapenko A. Biosimilars in rheumatology: a review of the evidence and their place in the treatment algorithm. Rheumatology 2017;56(suppl_4):iv30iv48.

2 Cohen H, Beydoun D, Chien D, et al. Awareness, knowledge, and perceptions of biosimilars among specialty physicians. Adv Ther 2017;33:2160-72.

3 Dörner T, Strand V, Cornes P, et al. The changing landscape of biosimilars in rheumatology. Ann Rheum Dis 2016;75:974-82.

4 Emery P, Vencovský J, Sylwestrzak A, et al. Long-term efficacy and safety in patients with rheumatoid arthritis continuing on SB4 or switching from reference etanercept to SB4. Ann Rheum Dis 2017:1986-91.
5 2018. European medicines agency assessment report, Benepali. Available from: http:// www.ema.europa.eu/docs/en_GB/document_library/EPAR_-_Public_assessment_ report/human/004007/WC500200380.pdf [Accessed Aug 2018]

6 Emery P, Vencovský J, Sylwestrzak A, et al. A phase III randomised, double-blind, parallel-group study comparing SB4 with etanercept reference product in patients with active rheumatoid arthritis despite methotrexate therapy. Ann Rheum Dis 2017;76:51-7

7 Tesser JR, Furst DE, Jacobs I. Biosimilars and the extrapolation of indications for inflammatory conditions. Biologics 2017;11:5-11.

8 Kay J, Schoels MM, Dörner T, et al. Consensus-based recommendations for the use of biosimilars to treat rheumatological diseases. Ann Rheum Dis 2018;77:165-74.

9 Braun J, Park W, Yoo DH, et al. FRI0119 what intrinsic and extrinsic factors affect the developement of anti-drug antibody to innovator infliximab and its biosimilar CT-P13 in rheumatoid arthritis and ankylosing spondylitis: Table 1. Ann Rheum Dis 2015;74(Suppl 2):463.2-4.

10 Braun J, Baraliakos X, Kudrin A. Striking Discrepancy in the Development of AntiDrug Antibodies (ADA) in Patients with Rheumatoid Arthritis (RA) and Ankylosing Spondylitis (AS) in Response to Infliximab (INF) and Its Biosimilar CT-P13. ACR annual meeting2014.

11 Danese S, Gomollon F, Governing Board and Operational Board of ECCO. ECCO position statement: the use of biosimilar medicines in the treatment of inflammatory bowel disease (IBD). J Crohns Colitis 2013;7:586-9.

12 Vashisht P, Sayles H, Cannella AC, et al. Generalizability of patients with rheumatoid arthritis in biologic agent clinical trials. Arthritis Care Res 2016;68:1478-88.

13 Zink A, Askling J, Dixon WG, et al. European biologicals registers: methodology, selected results and perspectives. Ann Rheum Dis 2009;68:1240-6.

14 Moots R, Azevedo V, Coindreau JL, et al. Switching between reference biologics and biosimilars for the treatment of rheumatology, gastroenterology, and dermatology inflammatory conditions: considerations for the clinician. Curr Rheumatol Rep 2017;19:37.

15 Cantini F, Benucci M. Switching from the bio-originators to biosimilar: is it premature to recommend this procedure? Ann Rheum Dis 2017:annrheumdis-2017-212820.

16 The Danish Regions, RADS, Guidelines for use of biosimilar infliximab and etanercept. 2018. Available from: http://www.regioner.dk/media/3488/rads-notat-omanvendelsen-af-biosimilaere-juni-2016.pdf [Accessed Aug 2018].

17 Glintborg B, Sørensen IJ, Loft AG, et al. A nationwide non-medical switch from originator infliximab to biosimilar CT-P13 in 802 patients with inflammatory arthritis: 1-year clinical outcomes from the DANBIO registry. Ann Rheum Dis 2017;76:1426-31.

18 Holroyd C, Wallis D, Bennet S. Switching from bio-original etanercept to biosimilar etanercept SB4: patient acceptability and outcomes in the real world (abstract). Ann Rheum Dis 2017;76(suppl 2):1180.

19 Sigurdardottir V, Husmark T, Svärd A. Switching from reference product etanercept to the biosimilar SB4 in a real life setting: follow-up of 147 patients (abstract). Ann Rheum Dis 2017;76(suppl 2):835.

20 Tweehuysen L, Huiskes VJB, van den Bemt BJF, et al. Open-label, non-mandatory transitioning from originator etanercept to biosimilar sb4: six-month results from a controlled cohort study. Arthritis Rheumatol 2018;70:1408-1418.

21 Ibfelt EH, Jensen DV, Hetland ML. The Danish nationwide clinical register for patients with rheumatoid arthritis: DANBIO. Clin Epidemio/ 2016:8:737-42.

22 2016. DANBIO's National Clinical Quality Report(Report in Danish). Available from: https://danbio-online.dk/formidling/DANBIOrsapport2016.pdf/view [Accessed Aug 2018].

23 Charlson ME, Pompei P, Ales KL, et al. A new method of classifying prognostic comorbidity in longitudinal studies: development and validation. J Chronic Dis 1987:40:373-83.

24 Lynge E, Sandegaard JL, Rebolj M. The danish national patient register. Scand J Public Health 2011;39(7 Suppl):30-3

25 Smolen JS, Landewé R, Bijlsma J, et al. EULAR recommendations for the management of rheumatoid arthritis with synthetic and biological disease-modifying antirheumatic drugs: 2016 update. Ann Rheum Dis 2017;76:960-77.

26 Glintborg B, Lindström U, Aaltonen K, et al. Biological treatment in ankylosing spondylitis in the Nordic countries during 2010-2016: a collaboration between five biological registries. Scand J Rheumatol 2018:1-10.

27 Araújo FC, Gonçalves J, Fonseca JE. Pharmacoeconomics of biosimilars: what is there to gain from them? Curr Rheumatol Rep 2016;18:50.

28 Uhlig T, Goll GL. Reviewing the evidence for biosimilars: key insights, lessons learned and future horizons. Rheumatology 2017;56(suppl_4):iv49-iv62.

29 Toussirot $E$, Marotte $H$. Switching from originator biological agents to biosimilars: what is the evidence and what are the issues? RMD Open 2017:3:e000492.

30 Hendricks 0 , Hørslev-Petersen K. When etanercept switch fails - clinical considerations (abstract). Arthritis Rheum 2017:69(suppl 10).

31 Emery P, Vencovský J, Ghil J, et al. Difference between SB4 and reference etanercept in the hepatobiliary disorders not considered to be caused by SB4: response to letter by Scheinberg and Azevedo. Ann Rheum Dis 2016;75:e65.

32 Jacobs I, Singh E, Sewell KL, et al. Patient attitudes and understanding about biosimilars: an international cross-sectional survey. Patient Prefer Adherence 2016; 10:937-48 
33 Waller J, Sullivan E, Piercy J, et al. Assessing physician and patient acceptance of infliximab biosimilars in rheumatoid arthritis, ankylosing spondyloarthritis and psoriatic arthritis across Germany. Patient Prefer Adherence 2017;11:519-30.

34 Planès S, Villier C, Mallaret M. The nocebo effect of drugs. Pharmacol Res Perspect 2016;4:e00208.

35 Colloca L. Tell me the truth and i will not be harmed: informed consents and nocebo effects. Am J Bioeth 2017;17:46-8.

36 Arnold MH, Finniss DG, Kerridge I. Medicine's inconvenient truth: the placebo and nocebo effect. Intern Med J 2014;44:398-405.
37 Tweehuysen L, van den Bemt BJF, van Ingen IL, et al. Subjective complaints as the main reason for biosimilar discontinuation after open-label transition from reference infliximab to biosimilar infliximab. Arthritis Rheumatol 2018;70:60-8.

38 Rezk MF, Pieper B. Treatment outcomes with biosimilars: be aware of the nocebo effect. Rheumatol Ther 2017;4:209-18.

39 Nikiphorou E, Kautiainen $\mathrm{H}$, Hannonen $\mathrm{P}$, et al. Clinical effectiveness of CT-P13 (Infliximab biosimilar) used as a switch from Remicade (infliximab) in patients with established rheumatic disease. Report of clinical experience based on prospective observational data. Expert Opin Biol Ther 2015;15:1677-83. 